\title{
Unsteady-state operation of supported platinum catalysts for high conversion of methane
}

\author{
Sheedeh Fouladvand, Magnus Skoglundh and, Per-Anders Carlsson \\ Department of Chemistry and Chemical Engineering, and Competence Centre for Catalysis, \\ Chalmers University of Technology, SE-412 96 Göteborg, Sweden
}

\begin{abstract}
Total oxidation of methane over model monolith catalysts with platinum supported on alumina, alumina-ceria and ceria has been studied under unsteadystate operation of the feed gas stoichiometry. The general activity for methane oxidation follows the order $\mathrm{Pt} /$ alumina $<\mathrm{Pt} /$ alumina-ceria $<\mathrm{Pt} /$ ceria. Thanks to high catalytic activity at the gas composition switches, increased cycling frequency between oxygen excess and oxygen free conditions increases the average methane conversion significantly from 11 to $58 \%$ for Pt/alumina and from 25 to $87 \%$ for Pt/alumina-ceria. The corresponding stationary methane conversion is 10 and $19 \%$, respectively. The underlying reason for the enhanced catalytic activity is likely twofold namely that periods with detrimentally high coverage of either oxygen or carbon are shortened and that the transients induce a highly active (chemical) state of the catalyst, thus, facilitating high average conversion of methane.

Keywords: transient reactor operation; enhanced catalyst efficiency; oxygen self-poisoning; methane activation
\end{abstract}

Email address: per-anders.carlsson@chalmers.se (Per-Anders Carlsson) 


\section{Introduction}

Industrial catalytic processes are generally operated at (nearly) steady-state conditions for many reasons, e.g., steady consumption of reactants and formation of products, optimal process conditions for high space-time yields and stability of the chemical reactor [1] motivated also by safety concerns. Despite this, operation of industrial catalytic processes at unsteady-state conditions may be beneficial in terms of catalytic activity and/or selectivity. This has been an area for research under long time and concepts like reversed-flow $[2,3]$ and pulsed supply of reactants [4] have been studied both experimentally and theoretically. Knowledge in unsteady-state operation is also important for safe start-up and shut-down of industrial chemical processes. Furthermore, there are processes that almost exclusively operate under unsteady-state conditions. Catalytic converters for automotive exhaust aftertreatment is probably the most important example here. In the so-called three-way catalyst (TWC) carbon monoxide, hydrocarbons, nitrogen oxides and oxygen simultaneously react to harmless products. The process is highly unsteady not only due to that vehicles more or less exclusively are driven at varying speed and load but also because deliberate cycling of the engine air-to-fuel ratio creates exhausts that continuously alternate between net-oxidizing and net-reducing composition. The TWC is highly efficient at elevated temperatures but considerably less effective at low temperatures.

To improve the low-temperature activity of TWCs, especially for the abatement of cold-start emissions, transient operation can be applied [5]. For example it has been shown that by use of periodic operation of the gas composition, the light-off temperature for conversion of hydrocarbons can be lowered by $50-75^{\circ} \mathrm{C}$ over a TWC $[6,7]$. In this case the benefit with periodic operation is mainly due to a lowering of the $\mathrm{CO}$ self-poisoning, which has previously been studied 
in detail $[8,9,10,11]$. Unsteady-state operation of the exhaust composition has been shown beneficial also for total oxidation of saturated hydrocarbons, e.g., methane $[12,13,14,15]$ and propane [16]. In these cases temporary high activity is observed during the switch from net-reducing to net-oxidising conditions and vice versa. For methane oxidation over alumina supported platinum this temporary high activity has been shown to stem either from the formation of a partially oxidized platinum surface that is more effective for dissociation of methane or, more likely, from a period with more reactive chemisorbed oxygen prior to oxide formation $[17,18]$. We mention that unsteady-state operation of the exhaust temperature also can be used to enhance the methane conversion over alumina supported platinum [19].

In the present study we consider the total oxidation of methane over supported platinum catalysts, i.e., $\mathrm{Pt} / \mathrm{Al}_{2} \mathrm{O}_{3}, \mathrm{Pt} / \mathrm{Al}_{2} \mathrm{O}_{3}-\mathrm{CeO}_{2}$ and $\mathrm{Pt} / \mathrm{CeO}_{2}$ monolith catalysts, specifically exploring the possibility of unsteady-state operation as to influence the (average) catalytic activity.

\section{Materials and methods}

Powder catalysts with 4 wt.- $\%$ Pt supported on $\mathrm{Al}_{2} \mathrm{O}_{3}, \mathrm{Al}_{2} \mathrm{O}_{3}-\mathrm{CeO}_{2}$ and $\mathrm{CeO}_{2}$ were prepared by incipient wetness impregnation [20]. The samples are from here referred to as $\mathrm{Pt} / \mathrm{Al}, \mathrm{Pt} / \mathrm{AlCe}$ and $\mathrm{Pt} / \mathrm{Ce}$, respectively. Transient activity tests were performed with monolith samples in a continuous gas-flow reactor, which has been described in detail elsewhere [21]. The monolith samples were prepared by coating $200 \mathrm{mg}$ of the respective powder catalyst onto cordierite monolith substrates $(\mathrm{L}=15 \mathrm{~mm}, \varnothing=12 \mathrm{~mm}$ ) as described in reference [20]. The inlet gas temperature $15 \mathrm{~mm}$ upstream the catalyst and the catalyst temperature were separately measured by type $\mathrm{k}$ thermocouples and a PID regulator was used to control the inlet gas temperature. The feed gas was controlled 
via a set of mass flow controllers (Bronkhorst LOW- $\Delta$ P-FLOW) and introduced to the reactor by air-actuated high-speed gas valves (Valco, VICI) that allow fast changes of the feed composition. The flow throughout the experiment was $500 \mathrm{ml} / \mathrm{min}$, corresponding to $15000 \mathrm{~h}^{-1}$ GHSV and a residence time of $0.2 \mathrm{~s}$. A mass spectrometer (Prisma, Pfeiffer) was used to measure the mass-to-charge ratio of the relevant components in the reactor outlet. The catalyst samples were pretreated with the feed gas consisting of 0.3 vol.- $\% \mathrm{O}_{2}$ and 0.1 vol.- $\%$ $\mathrm{CH}_{4}$ balanced with $\mathrm{Ar}$ at $400^{\circ} \mathrm{C}$ for 10 minutes. The transient experiment was then initiated by removing oxygen from the feed for a period of $300 \mathrm{~s}$ while simultaneously compensating with addition of Ar to maintain constant total flow, after which oxygen was added to the feed again for another $300 \mathrm{~s}$. This cycle was repeated before the same procedure was carried out with 150, 75, 50, 25,15 and $10 \mathrm{~s}$ pulsing intervals.

\section{Results and discussion}

The results from the transient flow reactor experiments are presented in Figures 1 and 2. Figure 1 shows the methane conversion over the three catalysts versus time. In the experiments the pulsing frequency is gradually increased, i.e, the duration of the oxygen pulse is gradually shortened as indicated with blue figures on top of Figure 1. It is clear for the Pt/alumina catalyst that the average methane conversion increases upon increasing pulsing frequency. For the alumina-ceria and ceria supported catalysts, the average methane conversion increases when the pulse length is successively shorted from 300 to 150, 75, 50, 25 and $15 \mathrm{~s}$ but for further shortening of the pulse length the average methane conversion remains unchanged. For each change of pulsing frequency (indicated by dashed lines) one cycle needs to be carried through before repeatable responses are established. Figure 2 zooms in on the responses in methane conversion, 
oxygen breakthrough, reaction products and carbon balance in the case of 300 , 150, 75 and $50 \mathrm{~s}$ pulse length. For the $\mathrm{Pt} / \mathrm{Al}$ catalyst the conversion of methane increases rapidly from about 8 to $35 \%$ when oxygen is removed from the feed at $\mathrm{t}=0 \mathrm{~s}$, followed by a decline towards $6 \%$ conversion for the remaining of the rich phase. Upon introduction of oxygen, the methane conversion increases rapidly and reaches $55 \%$. However, continuing the experiment under lean conditions, the methane conversion drops after about $30 \mathrm{~s}$ and approaches $8 \%$ during the remaining of the lean phase. After the drop in methane conversion the outlet oxygen concentration increases first rapidly and then more slowly towards 2700 ppm by the end of the lean phase. Partial oxidation products prevail during the rich phase while their production during the lean phase is negligible and the total oxidation is the dominant reaction. The same behaviour is seen for each pulse frequency. However, as a result of the shorter pulse lengths the decline in methane conversion during the rich phases is less pronounced and thus the average methane conversion increases as indicated by the horizontal dashed lines. Moving to the $\mathrm{Pt} / \mathrm{AlCe}$ catalyst, the same trend is observed although higher conversion levels of methane are achieved through the experiment and the maximum oxygen level reached by the end of the lean phase is lower as a result. A similar trend for reaction products is observed for Pt/AlCe except the longer time needed for the $\mathrm{Pt} / \mathrm{AlCe}$ sample to stabilize compared to the $\mathrm{Pt} / \mathrm{Al}$ sample. Moreover, the methane conversion peaks are both higher and broader for the $\mathrm{Pt} / \mathrm{AlCe}$ catalyst compared to the $\mathrm{Pt} / \mathrm{Al}$ sample. In contrast to the alumina containing catalysts the $\mathrm{Pt} / \mathrm{Ce}$ catalyst is highly active throughout the lean phases and thus unsteady-state operation is not beneficial at this temperature. However, at lower temperatures unsteady-state operation may be useful also for ceria-based platinum catalysts as reported previously [14]. Clearly, at the introduction of the lean phase, complete conversion of methane is reached 
quickly while the oxygen breakthrough is significantly delayed. For pulse lengths from $75 \mathrm{~s}$ and below no oxygen breakthrough is observed. The average oxygen consumption reported in Table 1 indicates significant oxygen storage for this sample. This is due to the ability of cerium to readily change oxidation state (between Ce(III) and Ce(IV)) thereby functioning as an oxygen buffer [24]. The pattern for reaction product formation is more complicated for the $\mathrm{Pt} / \mathrm{Ce}$ sample. Noteworthy is the considerable amounts of carbon containing species being formed during the rich phases which are oxidized at the introduction of the lean phases.

As shown in Figure 2, the introduction of the lean/rich phase is always accompanied by a temporary maximum in methane conversion for the alumina containing catalysts, which can be explained based on the sensitivity of the methane oxidation reaction to the surface $\mathrm{O} / \mathrm{Pt}$ ratio [18], and by achieving an optimal adsorbate composition on the platinum surface through pulsing which leads to high methane conversion [13]. The electronic state of platinum is dependent on the oxidizing/reducing character of the feed. According to Szlachetkoi et al. [22], by switching from reducing to oxidizing environment, prior to platinum oxide formation, the platinum surface proceeds through an intermediate state with strong contribution from chemisorbed oxygen. However, no such state was reported at the switches from oxidizing to reducing conditions [22]. Furthermore, Becker et al. also discussed formation of more reactive chemisorbed oxygen on the platinum surface before oxide formation, as a probable cause of the temporary increased activity at the switches [18].

If the optimal surface composition during the periods with temporary high methane conversion is identified, preserving this active state would of course increase the overall activity for methane oxidation. The purpose of this experiment is to keep the system closer to the most active state, i.e. the catalyst state 
at the switches. Table 1 shows the average conversion (defined as the integrated methane conversion over a period with reproducible pulses) and the corresponding average oxygen conversion for all pulse frequencies. The corresponding stationary methane conversions are reported as well. For the alumina-containing catalysts the average conversion of both methane and oxygen increase with increased pulsing frequency. For $\mathrm{Pt} / \mathrm{Al}_{2} \mathrm{O}_{3}$ monolith catalyst this effect has previously been predicted by simulations [13]. The simulations showed that with a suitable pulse sequence, periods with either too high oxygen or too high carbon coverage on the active sites are shortened, resulting in higher reaction rate and an increased overall conversion of methane.

The general activity for methane oxidation from these experiments follows the order $\mathrm{Pt} / \mathrm{Al}<\mathrm{Pt} / \mathrm{AlCe}<\mathrm{Pt} / \mathrm{Ce}$, i.e. higher activity is achieved by increasing the ceria content of the catalyst. Beside the oxygen storage/release capacity of ceria [24] and the active Pt-Ce interface sites [14, 23], another possible reason behind the superior performance of the ceria containing catalysts could be that ceria promotes reduction of oxidized/oxygen covered platinum and lowers the formation of carbon on the active catalyst surface [25], which can contribute to circumvent the periods with low methane conversion.

\section{Conclusions}

We show experimentally that transient operation can be used to improve the conversion of self-poisoned reactions such as methane oxidation over platinum based catalysts. By appropriate choice of support material for the catalysts and operational mode, the overall catalytic efficiency for methane oxidation can be improved considerably. It is clearly shown that alumina supported platinum catalysts respond well to transient operation, i.e., the methane conversion is significantly improved as compared to the steady-state conditions. For the 
$\mathrm{Pd} / \mathrm{Al}$ catalyst the stationary methane conversion is $10 \%$ whereas with increasing frequency of the gas composition changes the average conversion of methane increases from about 11 to $58 \%$.

\section{Acknowledgments}

The authors would like to thank the Swedish Foundation for Strategic Research (SSF) and the Competence Centre for Catalysis, which is hosted by Chalmers University of Technology and financially supported by the Swedish Energy Agency and the member companies AB Volvo, ECAPS AB, Haldor Topsøe A/S, Volvo Car Corporation AB, Scania CV AB, and Wärtsilä Finland Oy.

[1] R. Aris, Elementary chemical reactor analysis, General Publishing Company, Ltd. Toronto, Canada,1989.

[2] R. Q. Ferreira, C. A. Costa and S. Masetti, Reverse-flow reactor for a selective oxidation process, Chem. Eng. Sci. 54 (1999) 4615-4627.

[3] Y. S. Matros and G. A. Bunimovich, Reverse-flow operation in fixed bed catalytic reactors, Catal. Rev. Sci. Eng. 38 (1996) 1-68.

[4] X. Ni, M. R. Mackley, A. P. Harvey, P. Stonestreet, M. H. I. Baird and N. V. Rama Rao, Mixing through oscillations and pulsations - a guide to achieving process enhancements in the chemical and process industries, Chem. Eng. Res. Des. 81 (2003) 373-383.

[5] H. Shinjoh, H. Muraki, Y. Fujitani, Periodic operation effects on automotive noble metal catalysts - reaction analysis of binary gas systems, Catalysis and Automative Pollution Control (1987) 187-197. 
[6] S. Tagliaferri, R. Köppel, A. Baiker, Behavior of non-promoted and ceriapromoted $\mathrm{Pt} / \mathrm{Rh}$ and $\mathrm{Pd} / \mathrm{Rh}$ three-way catalysts under steady state and dynamic operation of hybrid vehicles, Ind. Eng. Chem. Res. 38 (1999) 108117.

[7] M. Skoglundh, P. Thormählen, E. Fridell, F. Hajbolouri and E. Jobson, Improved light-off performance by using transient gas compositions in the catalytic treatment of car exhausts, Chem. Eng. Sci. 54 (1999) 4559-4566.

[8] J. H. B. J. Hoebink, A. J. L. Nievergeld and G. B. Marin, CO oxidation in a fixed bed reactor with high frequency cycling of the feed, Chem. Eng. Sci. 54 (1999) 4459-4468.

[9] P.-A. Carlsson, P. Thormählen, M. Skoglundh, H. Persson, E. Fridell, E. Jobson and B. Andersson, Periodic control for improved low-temperature catalytic activity, Top. Catal. 16/17(1-4) (2001) 343-347.

[10] P.-A. Carlsson, M. Skoglundh, E. Fridell, E. Jobson and B. Andersson, Induced low temperature catalytic ignition by transient changes in the gas composition, Catal. Today 73 (2002) 307-313.

[11] P.-A. Carlsson, M. Skoglundh, P. Thormählen and B. Andersson, Lowtemperature $\mathrm{CO}$ oxidation over a $\mathrm{Pt} / \mathrm{Al}_{2} \mathrm{O}_{3}$ monolith catalyst investigated by step-response experiments and simulations, Top. Catal. 31/31 (2004) $375-381$.

[12] P.-A. Carlsson, E. Fridell, M. Skoglundh, Methane oxidation over Pt $/ \mathrm{Al}_{2} \mathrm{O}_{3}$ and $\mathrm{Pd} / \mathrm{Al}_{2} \mathrm{O}_{3}$ catalysts under transient conditions, Catal. Lett. 115(1-2) (2007) 1-7.

[13] P.-A. Carlsson, M. Nordström and M. Skoglundh, Virtual control for high conversion of methane over supported Pt, Top. Catal. 52 (2009) 19621966. 
[14] E. Becker, P.-A. Carlsson and M. Skoglundh, Methane oxidation over alumina and ceria supported platinum, Top. Catal. 52 (2009) 1957-1961.

[15] D. Bounechada, G. Groppi, P. Forzatti and T. Kinnunen, Effect of periodic lean/rich switch on methane conversion over a Ce?Zr promoted Pd$\mathrm{Rh} / \mathrm{Al}_{2} \mathrm{O}_{3}$ catalyst in the exhausts of natural gas vehicles, Appl. Catal. B. Environ. 119-120 (2012) 91-99.

[16] P.-A. Carlsson, S. Mollner, K. Arnby and M. Skoglundh, Effect of periodic operation on the low-temperature activity for propane oxidation over Pt $/ \mathrm{Al}_{2} \mathrm{O}_{3}$ catalysts, Chem. Eng. Sci. 59 (2004) 4313-4323.

[17] E. Becker, P.-A. Carlsson, H. Grönbeck and M. Skoglundh, Methane oxidation over alumina supported platinum investigated by time-resolved in situ XANES spectroscopy, J. Catal. 252 (2007) 11-17.

[18] E. Becker, P.-A. Carlsson, L. Kylhammar, M. Newton and M. Skoglundh, In situ spectroscopic investigation of low-temperature oxidation of Methane over alumina-supported platinum during periodic operation, J. Phys. Chem. C 115 (2010) 944-951.

[19] A. Amin, A. Abedi, R. Hayes, M. Votsmeier, W. Epling, Methane oxidation hysteresis over Pt/ $\mathrm{Al}_{2} \mathrm{O}_{3}$, Appl. Catal. A: Gen. 478 (2014) 91-97.

[20] S. Fouladvand, M. Skoglundh and P.-A. Carlsson, A transient in situ infrared spectroscopy study on methane oxidation over supported Pt catalysts, Catal. Sci. Technol. 4(10) (2015) 3463-3473.

[21] D. Bounechada, S. Fouladvand, L. Kylhammar, T. Pingel, E. Olsson, M. Skoglundh, J. Gustafson, M. Di Michiel, M. A. Newton and P.-A. Carlsson, Mechanisms behind sulfur promoted oxidation of methane, Phys. Chem. Chem. Phys. 15 (2013) 8648-8661. 
[22] J. Szlachetko, D. Ferri, V. Marchionni, A. Kambolis, O. V. Safonova, C. J. Milne, O. Kröcher, M. Nachtegaal and J. Sa, Subsecond and in situ chemical speciation of $\mathrm{Pt} / \mathrm{Al}_{2} \mathrm{O}_{3}$ during oxidation - reduction cycles monitored by high-energy resolution off-resonant x-ray spectroscopy, J. Am. Chem. Soc. 135 (2013) 19071-19074.

[23] L. Kylhammar, P.-A. Carlsson and M. Skoglundh, Sulfur promoted lowtemperature oxidation of methane over ceria supported platinum catalysts, J. Catal. 284 (2011) 50-59.

[24] A. Trovarelli, Catalytic properties of ceria and $\mathrm{CeO}_{2}$-containing materials, Catal. Rev. Sci. Eng. 38 (1996) 439-520.

[25] A. Piras, A. Trovarelli and G. Dolcetti, Remarkable stabilization of transition alumina operated by ceria under reducing and redox conditions, Appl. Catal. B: Env. 28 (2000) L77-81. 


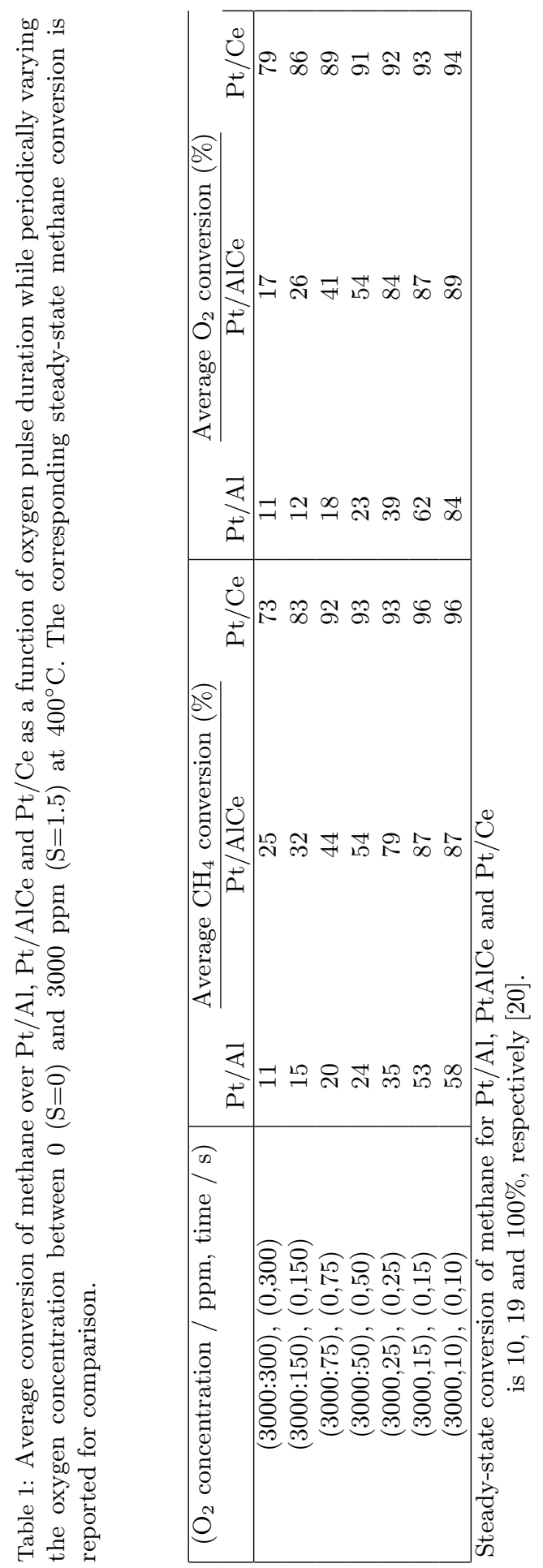




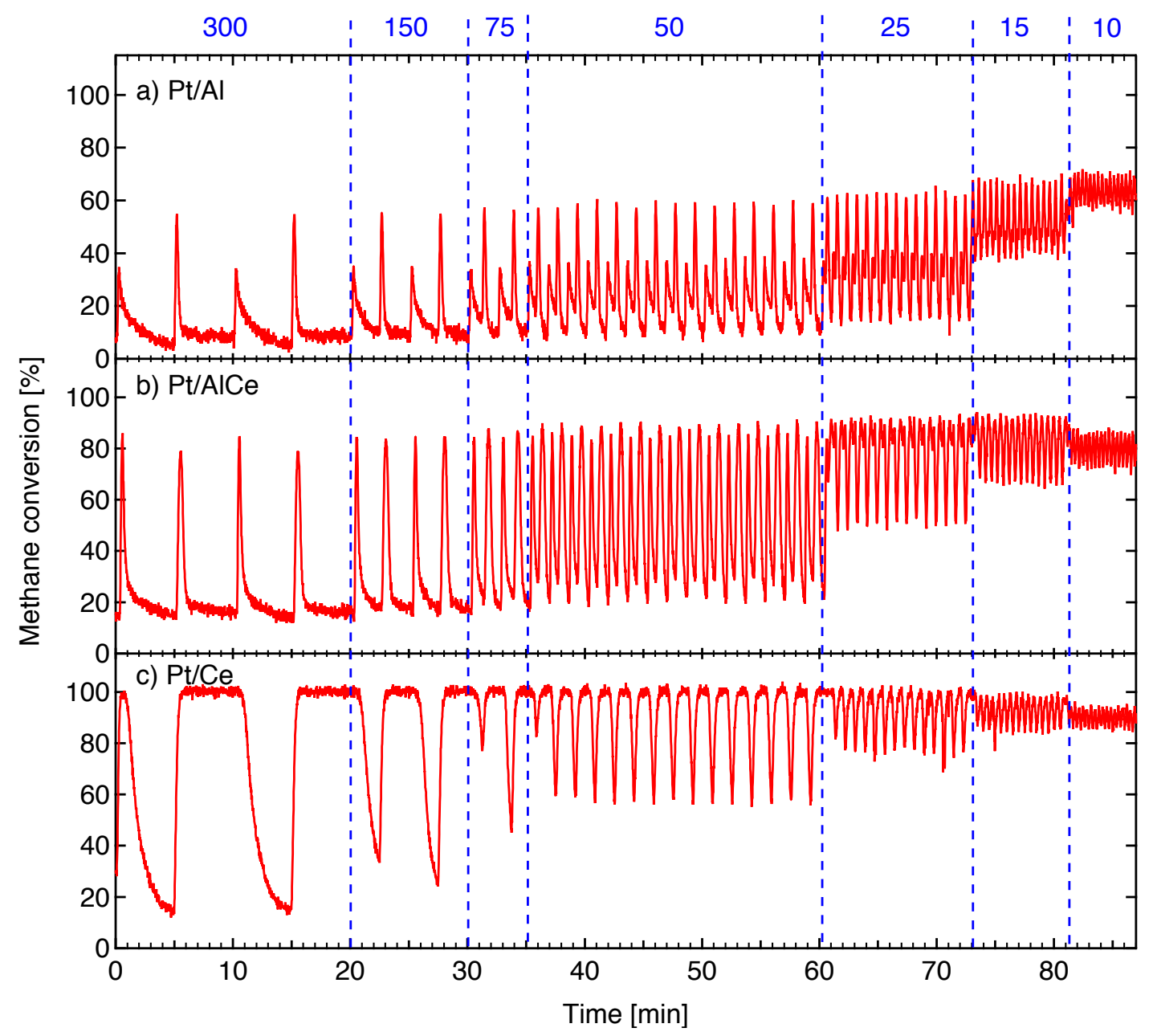

Figure 1: Oxidation of $0.1 \% \mathrm{CH}_{4}$ over a) 4-wt.\% Pt/ $/ \mathrm{Al}_{2} \mathrm{O}_{3}$, b) 4-wt.\% $\mathrm{Pt} / \mathrm{Al}_{2} \mathrm{O}_{3}-\mathrm{CeO}_{2}$ and c) 4 -wt. $\% \mathrm{Pt} / \mathrm{CeO}_{2}$ catalysts while periodically varying the oxygen concentration between 0 $(\mathrm{S}=0)$ and $3000 \mathrm{ppm}(\mathrm{S}=1.5)$ at $400^{\circ} \mathrm{C}$, with pulse lengths $300,150,75,50,25$, and $10 \mathrm{~s}$. 
a) $\mathrm{Pt} / \mathrm{Al}$

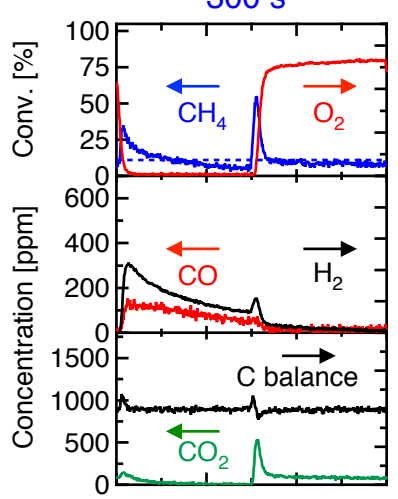

b) Pt/AICe

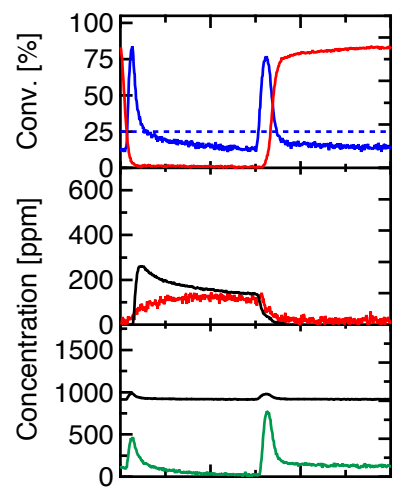

c) $\mathrm{Pt} / \mathrm{Ce}$

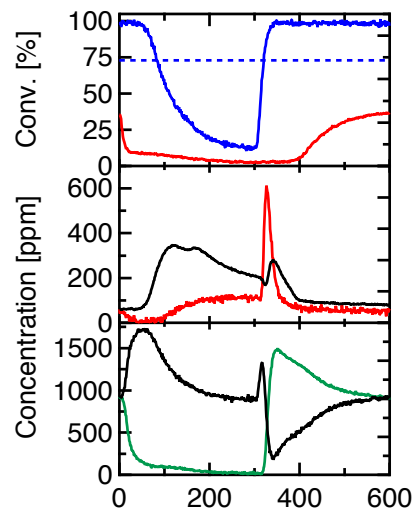

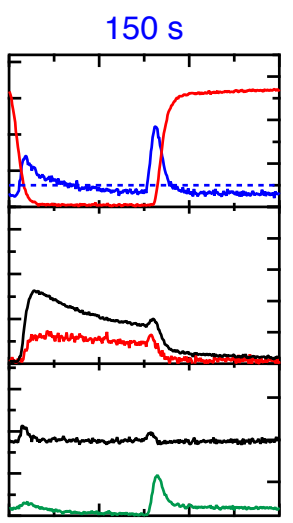
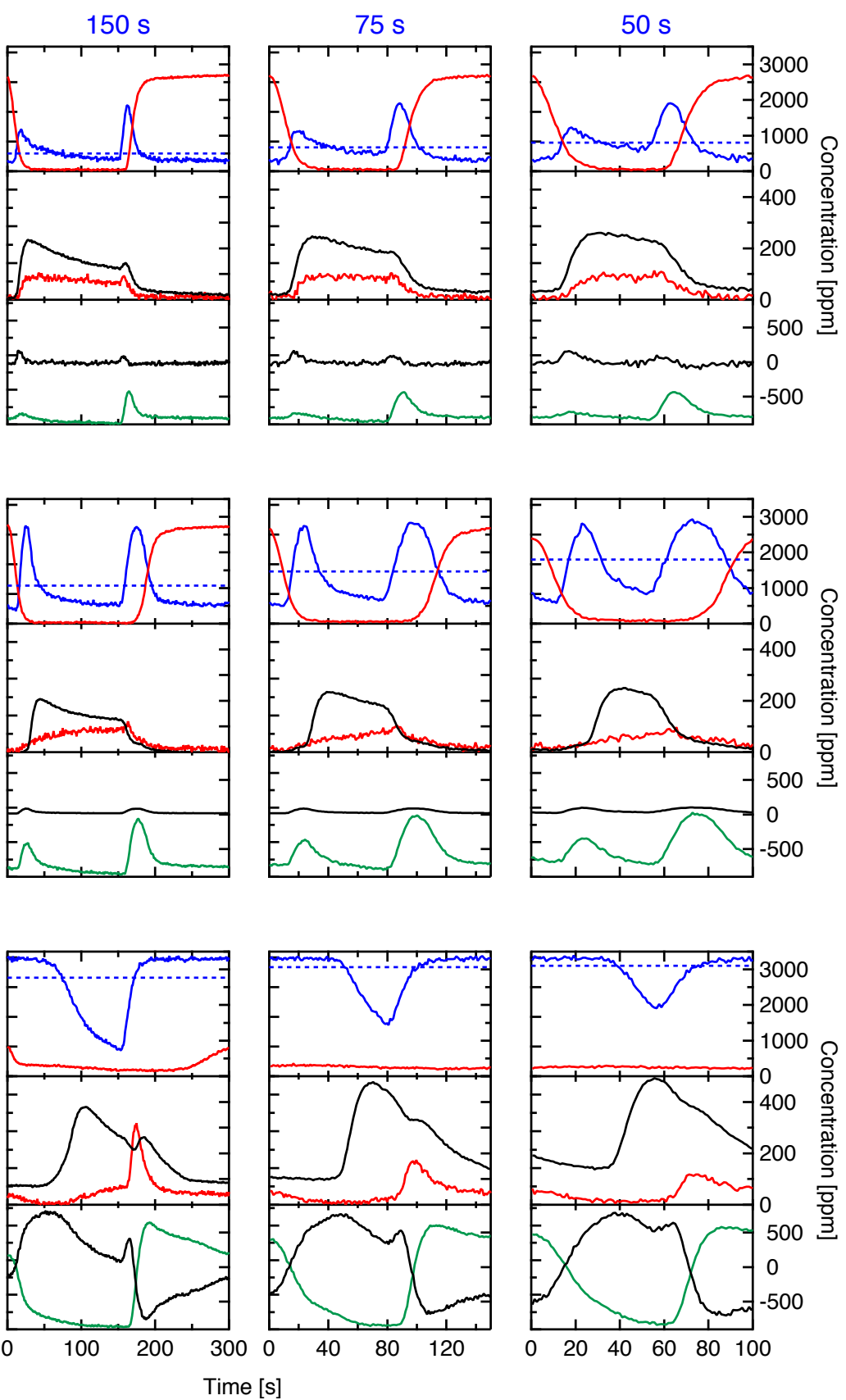

Figure 2: Oxidation of $0.1 \% \mathrm{CH}_{4}$ over 4 -wt. $\% \mathrm{Pt} / \mathrm{Al}_{2} \mathrm{O}_{3}$ (top panels), 4-wt.\% Pt/ $\mathrm{Al}_{2} \mathrm{O}_{3}-\mathrm{CeO}_{2}$ (middle panels) and 4 -wt.\% $\mathrm{Pt} / \mathrm{CeO}_{2}$ (bottom panels) catalysts while periodically varying the oxygen concentration between $0(\mathrm{~S}=0)$ and $3000 \mathrm{ppm}(\mathrm{S}=1.5)$ at $400^{\circ} \mathrm{C}$, with pulse lengths $300,150,75$ and $50 \mathrm{~s}$. The dotted line shows the average methane conversion. 